Tropical Journal of Pharmaceutical Research July 2019; 18 (7): 1499-1506

ISSN: $1596-5996$ (print); 1596-9827 (electronic)

(C) Pharmacotherapy Group, Faculty of Pharmacy, University of Benin, Benin City, 300001 Nigeria.

\title{
Antioxidant, anti-inflammatory and anti-arthritic activities of methanol extract of Tamus communis L. roots
}

\author{
Nacer Amraoui, Nozha Mayouf, Noureddine Charef, Abderrahmane Baghiani, \\ Lekhmici Arrar* \\ Laboratory of Applied Biochemistry, Faculty of Nature and Life Sciences, University Ferhat Abbas Setif 1, Setif 19000 Algeria \\ *For correspondence: Email: lekharrar@hotmail.com; Tel: + (213)666466220
}

Sent for review: 19 February 2019

Revised accepted: 24 June 2019

\begin{abstract}
Purpose: To evaluate the antioxidant, anti-inflammatory and anti-arthritic effects of the methanol extract of Tamus communis roots.

Methods: The total phenolic and flavonoid contents were determined using Folin-Ciocalteu's reagent and aluminium chloride assays, respectively while the antioxidant capacity was determined using DPPH and $\beta$-carotene/linoleate tests. For anti-inflammatory activity, carrageenan-induced paw edema in rat was used. Formaldehyde-induced paw edema and adjuvant-induced arthritis in rats were used to evaluate the anti-arthritic effect of the extract.

Results: The total phenolic and flavonoid contents of T. communis showed $55.2 \pm 0.036 \mathrm{mg}$ GAE/g dry weight and $1.191 \pm 0.002 \mathrm{mg} Q E q / g$ dry weight, respectively while the antioxidant activity (DPPH) showed a half-maximal inhibitory concentration $\left(I C_{50}\right.$ of $0.128 \pm 0.011 \mathrm{mg} / \mathrm{mL}$. Using $\beta$ carotene/linoleate assay, the extract showed $88.13 \pm 4.03 \%$ inhibition. In carrageenan-induced paw edema in rat, all doses of $T$. communis did not show inhibition of edema. In contrast, formaldehydeinduced paw edema decreased at the dose of $150 \mathrm{mg} / \mathrm{kg}$ days 2 and 4 . However, doses of 300 and 600 $\mathrm{mg} / \mathrm{kg}$ did not show any activity. In adjuvant-induced arthritis, all used doses caused no reduction in arthritic scores and in paw thickness except a significant decrease with the dose $150 \mathrm{mg} / \mathrm{kg}$ at the last day.

Conclusion: T. communis extract exhibits high antioxidant activity related to the phenolic compound contents. However, the results of the anti-inflammatory and anti-arthritic studies did not support its use in folk medicine in the treatment of rheumatic ailment except on low doses
\end{abstract}

Keywords: Tamus communis, DPPH, Formaldehyde-induced paw edema, Adjuvant-induced arthritis, Anti-inflammatory, Anti-arthritic

This is an Open Access article that uses a fund-ing model which does not charge readers or their institutions for access and distributed under the terms of the Creative Commons Attribution License (http://creativecommons.org/licenses/by/4.0) and the Budapest Open Access Initiative (http://www.budapestopenaccessinitiative.org/read), which permit unrestricted use, distribution, and reproduction in any medium, provided the original work is properly credited.

Tropical Journal of Pharmaceutical Research is indexed by Science Citation Index (SciSearch), Scopus, International Pharmaceutical Abstract, Chemical Abstracts, Embase, Index Copernicus, EBSCO, African Index Medicus, JournalSeek, Journal Citation Reports/Science Edition, Directory of Open Access Journals (DOAJ), African Journal Online, Bioline International, Open-J-Gate and Pharmacy Abstracts

\section{INTRODUCTION}

The human body has a complex system of natural enzymatic and non-enzymatic antioxidant defences that neutralize the harmful effects of free radicals and other oxidants [1]. Free radicals and other reactive oxygen species (ROS) produced in living organisms caused many diseases including cancer, cardiovascular diseases, cataracts, asthma, hepatitis, liver injury 
and immunodeficiency diseases [2]. Studies on medicinal plants have indicated the presence of antioxidants such as phenolics, flavonoids, tannins, and proanthocyanidins. The ingestion of natural antioxidants has been inversely associated with morbidity and mortality from degenerative disorders [3]. Inflammatory processes lead to tissue injury in autoimmune diseases and other inflammatory conditions. Rheumatoid arthritis (RA) is a multi-factorial chronic inflammatory disease [4]. Currently available drugs for treatment of rheumatoid arthritis include analgesics, steroids, nonsteroidal anti-inflammatory drugs (NSAIDs), disease-modifying anti-rheumatic drugs (DMARDs) and immunosuppressive agents, which have potential side effects such as gastrointestinal tract, blood cell count, hair and immune system. As a result, new drugs that offer effective treatment with less side effects and relatively cheaper are needed. Thus, natural phytochemicals could serve as a better alternative strategy for the effective treatment of rheumatoid arthritis [5].

Tamus communis L. (Dioscoreaceae), called ElKarma Saouda, is a herbal species widely distributed in northern Algeria and used in traditional medicine to reduce inflammatory pain. Rhizomes and berries have been reported to be used to treat rheumatism, arthrosis, lumbago and dermatosis [6].

The objectives of this study were planned to evaluate in vitro antioxidant activity and in vivo anti-inflammatory and anti-arthritic activities in animal models of the methanol extract of $T$. communis roots.

\section{EXPERIMENTAL}

\section{Plant material}

The roots of $T$. communis were collected from Bougaa, Setif, northeast of Algeria, and authenticated by B. Oudjhih, University Batna, Algeria. Roots were cut into pieces, air-dried and powdered. The ground material $(2 \mathrm{~kg})$ was extracted with $10 \mathrm{~L}$ of methanol for one week at room temperature. The extract was filtered through Whatman filter paper to obtain particle free extract. The extract was pooled and concentrated and dried under vacuum in a rotavapor. Finally, the extract was kept at $4^{\circ} \mathrm{C}$ until use [7].

\section{Animals}

Adult female Wistar albino rats weighing 150 $170 \mathrm{~g}$ and female Swiss albino mice weighing 25
- $30 \mathrm{~g}$, purchased from 'Institut Pasteur d'Algérie', Algiers, were used for the study. The animals were housed in the clean plastic cages and maintained under standard laboratory conditions (temperature, $20-22^{\circ} \mathrm{C}$; relative humidity, $50-70 \%$, and 12/12 h light/ dark cycle). Water and feed were freely available. The animals were acclimatized (laboratory conditions) for one week prior to the experiment. The experiments were conducted in accordance with the internationally acceptable guidelines for evaluation the safety and efficacy of herbal medicines [8].

\section{Acute toxicity study}

Acute toxicity test was performed according to the organization for economic corporation and development (OECD-423) guidelines [8], with slight modifications. Three adult mice were fasting overnight with free access to water. After that, $T$. communis extract was orally administered at a dose of $5 \mathrm{mg} / \mathrm{kg}$ body weight. The mortality was observed for three days. If two or three animals died, the dose administered is considered as toxic. However, if only one mouse died, the experiment was repeated to confirm the toxicity. If no mortality was observed, higher doses 50,300 and $2000 \mathrm{mg} / \mathrm{kg}$ body weight were investigated. Animals were observed for toxic symptoms such as behaviour, body weight changes, locomotion and mortality during 14 days.

\section{Determination of total polyphenols and flavonoids}

Total phenolic in the methanol extract of $T$. communis was determined using Folin-Ciocalteu reagent, according to Boussoualim et al. [9]. Briefly, $0.1 \mathrm{~mL}$ of sample or standard (dissolved in methanol or distilled water) was mixed with 0.5 $\mathrm{ml}$ of Folin-Ciocalteu reagent (diluted to $1 / 10$ ). After $4 \mathrm{~min}, 0.4 \mathrm{ml}$ of $7.5 \% \mathrm{Na}_{2} \mathrm{CO}_{3}$ solution was added. The final mixture was shaken, incubated for $90 \mathrm{~min}$. in dark at room temperature and then the absorbance was measured spectrophotometrically (thermo spectronic, Helios Epsilon, USA) at $765 \mathrm{~nm}$. The results were expressed in $\mathrm{mg}$ Gallic acid equivalent $(\mathrm{GAE}) / \mathrm{g}$ of dry weight of dry powder.

Total flavonoids content of the extract were determined using the aluminium chloride colorimetric method. Quercetin was used as a standard. One $\mathrm{ml}$ of diluted sample (in methanol) was mixed with $1 \mathrm{ml}$ of $2 \%$ aluminium chloride in methanol. After incubation at room temperature for $10 \mathrm{~min}$, the absorbance of the mixture was measured at $430 \mathrm{~nm}$ and flavonoids are 
expressed as $\mathrm{mg}$ quercetin equivalent $(\mathrm{Q}-\mathrm{Eq}) / \mathrm{g}$ of dry powder [9].

\section{DPPH scavenging assay}

The free radical scavenging activity against DPPH radical was measured using the method described by Aouachria et al [7]. A volume of 50 $\mu \mathrm{l}$ of different dilutions of the extract was added to $1250 \mu \mathrm{L}$ of $4 \%$ solution DPPH dissolved in methanol. After an incubation period of $30 \mathrm{~min}$ in dark at room temperature, the absorbance was read at $517 \mathrm{~nm}$. Butylated hydroxytoluene $(\mathrm{BHT})$ was used as standard. The ability to scavenge the DPPH radical was calculated by using the following equation:

Scavenging effect $\%=100 \times($ Ac-As $) / A c$

where Ac: control absorbance and As: absorbance in the presence of extracts. The $\mathrm{IC}_{50}$ values (the concentration required to scavenge $50 \%$ DPPH free radicals) were calculated.

\section{$\beta$-Carotene bleaching assay}

The $\beta$-Carotene bleaching assay was conducted according to Aouachria et al [7] by measuring the inhibition of hydroperoxides formed from linoleic acid oxidation. A stock solution of $\beta$ carotene/linoleic acid mixture was prepared as follows: $0.5 \mathrm{mg} \beta$-carotene was dissolved in $1 \mathrm{~mL}$ of chloroform, and then $25 \mu \mathrm{L}$ linoleic acid and $200 \mathrm{mg}$ Tween 40 were added in the flask. The chloroform was completely evaporated under vacuum in a rotavapor at $40^{\circ} \mathrm{C}$. A volume of 100 $\mathrm{mL}$ of distilled water saturated with oxygen was added with vigorous shaking to form emulsion. Extract prepared in methanol $(350 \mu \mathrm{L})$ at a concentration of $2 \mathrm{mg} / \mathrm{mL}$, was added to $2500 \mu \mathrm{L}$ of reaction mixture. The absorbance of the mixture was measured at $470 \mathrm{~nm}$ after $0,1,2,4$, $6,12,24$ and $48 \mathrm{~h}$ of incubation. BHT was used as a positive standard. The rate of bleaching of $\beta$-carotene was calculated as antioxidant activity (AA) and calculated using Eq 1.

$A A=\left(A_{t} / A_{0}\right) 100$

where $A_{t}$ : absorbance in time $t$ and $A_{0}$ : absorbance in time 0 .

\section{Carrageenan-induced paw edema in rats}

Five groups of adults rats ( $n=5$ in each group) received plant extract $(150,300,600 \mathrm{mg} / \mathrm{kg}$ ), Diclofenac $(10 \mathrm{mg} / \mathrm{kg})$ or aqueous solution (vehicle control). Acute inflammation was induced by injection of $0.1 \mathrm{~mL}$ of Carrageenan $(\mathrm{k}$ carrageenan, Type IV, Sigma), 1\% (w/v) in $\mathrm{NaCl}$
$0.9 \%$ into the subplantar region of the right paw under moderate anesthesia [10]. The thickness of the paws was measured before and hourly after carrageenan injection using a digital calliper for $6 \mathrm{~h}$. The drugs were administered orally at $1 \mathrm{~h}$ before carrageenan injection. The percentage swelling of the paws was calculated following Eq 2:

$\%$ increase in paw thickness $=100 \times\left(D_{t}-D_{0}\right) / D_{0}$ (2)

where $D_{0}$ and $D_{t}$ are the paw thickness before and at $t$ time of the induction of the edema, respectively

\section{Induction of arthritis by formaldehyde}

Arthritis syndrome was produced by the method of Akindele and Adeyemi [11] with slight modifications. Chronic phase of inflammation was induced in rats by subcutaneous injection of $0.1 \mathrm{~mL}(2.5 \% \mathrm{v} / \mathrm{v}$ in normal saline) formaldehyde solution into the sub-plantar region of right hind paw of Wistar albino rats on first and third day of the experiment. The rats were divided into five groups ( $n=5$ in each group) as follows: group I: was the vehicle control which received aqueous solution, group II: received aspirin $150 \mathrm{mg} / \mathrm{kg}$, and groups III, IV and V: received 150, 300 and $600 \mathrm{mg} / \mathrm{kg}$ of $T$. communis extract, respectively. Rats of all groups were orally treated one hour before injection of formaldehyde, and then daily for 10 days. The paw thicknesses of rats were measured on days $0,2,4,6,8$ and 10 using a digital calliper. The mean percent increase or decrease in paw thickness for each treatment was calculated.

\section{Adjuvant-induced arthritis (AIA)}

Arthritis was induced according to method described earlier [12], by subplantar injection of $0.1 \mathrm{~mL}$ of complete Freund's adjuvant (CFA) in the right hind paw of rats subjected to light diethyl ether anaesthesia.

Six groups of 6 rats each were subjected to different treatments as follows: Group I: nonarthritic healthy rats: received aqueous solution, group II: rats with AIA and received aqueous solution, group III: rats with AIA and received diclofenac (3 $\mathrm{mg} / \mathrm{kg}$ ) and groups IV, V and VI: rats with AIA and treated with $T$. communis extract 150,300 and $600 \mathrm{mg} / \mathrm{kg}$, respectively. After AIA induction, the treatments were intragastrically administered once per day consecutively for 28 days. Anti-arthritic activity of $T$. Communis was evaluated by following parameters arthritic score, joint diameter and 
body weight just before immunization and on days $4,8,12,16,20,24$, and day 28 .

\section{Evaluation of hind paw swelling}

In order to evaluate the progression of AIA, the thickness of the right hind paws of all animals was measured just before immunization(day 0 ) and thereafter continued every four days till day 28 using a digital calliper to measure ankle (tibiotarsal) joint width [13]. The mean percent increase in paw thickness was calculated.

\section{Assessment of arthritis scores}

The rats were evaluated every four days for signs of arthritis between days 8 and 28 following immunization using a well-established, widely used scoring system developed to assess the severity of AIA. The severity of arthritis was assessed by erythema and swelling using a 4points / leg scale: $0=$ no sign of disease; $1=$ paws with swelling of the fingers; 2 = paws with slight swelling of the ankle or wrist joints; $3=$ paws with severe swelling and erythema; and $4=$ paws with deformity or ankylosis [14]. The total score of each animal was calculated as the arthritis index, with a possible maximum score of 8 (4 points $\times 2$ hind legs).

\section{Spleen index determination}

The spleen of all rats was removed after the sacrifice of the animals, and then weighed immediately. Spleen index was expressed as the ratio $(\mathrm{mg} / \mathrm{g})$ of spleen wet weight versus body weight [15].

\section{Statistical analysis}

The results are expressed as mean \pm SD (in vitro) and as mean \pm SEM (in vivo). Statistical analysis was done by means of the GraphPad Prism Software (version 7.0). Data were analyzed using Student's $t$ test and one-way analysis of variance (ANOVA), followed by Dunnett test for multiple comparison. The differences were considered to be significant at $p$ $<0.05$.

\section{RESULTS}

\section{Total polyphenol and flavonoid contents}

The methanol extract of $T$. communis showed a yield of $9.9 \%$. Total phenolic content was $55.2 \pm$ $0.036 \mathrm{mg} \mathrm{GAE} / \mathrm{g}$ of dry weight and a total flavonoids content was $1.191 \pm 0.002 \mathrm{mg} \mathrm{Q}-\mathrm{Eq} / \mathrm{g}$ of dry powder dry weight.

\section{DPPH scavenging assay}

The methanol extract of $T$. communis showed an $I_{50}$ value of $0.128 \pm 0.011 \mathrm{mg} / \mathrm{mL}$. For comparison, $\mathrm{BHT}$ showed an $\mathrm{IC}_{50}$ value of 0.087 $\pm 0.001 \mathrm{mg} / \mathrm{mL}$.

\section{$\beta$-Carotene bleaching assay}

Results in figure 1 showed the inhibition of $\beta$ carotene oxidation in the presence of $2 \mathrm{mg} / \mathrm{ml}$ of the extract or reference antioxidant (BHT) after $24 \mathrm{~h}$ of incubation. T. communis exhibited high antioxidant activity $(88.13 \pm 4.03 \%)$, which was near to that of BHT $(99.01 \pm 1.32 \%)$ used as positive control. The results indicate that Tamus communis demonstrated a significant $(p<0.001)$ increase in activity compared to negative control $(\mathrm{MeOH})$.

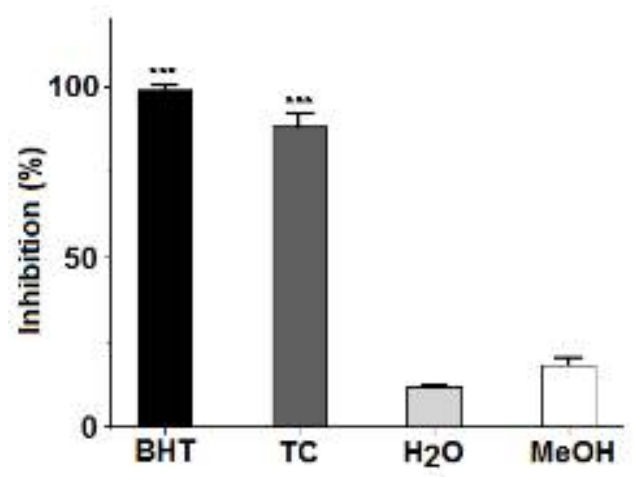

Figure 1: Antioxidant activities of $T$. communis extract ( $2 \mathrm{mg} / \mathrm{mL}$ at $24 \mathrm{~h}$ of incubation) measured by $\beta$ carotene bleaching method. Values are means \pm SD $(\mathrm{n}=3) .{ }^{* * *} p<0.001$, compared to negative control $(\mathrm{MeOH})$

\section{Acute toxicity}

All doses of $T$. communis extract studied do not show any toxic symptoms or mortality. Therefore, three doses $(150,300$ and $600 \mathrm{mg} / \mathrm{kg}$ body weight) were selected for the biological evaluation.

\section{Carrageenan-induced paw edema in rats}

Results showed that in control animals, the injection of carrageenan produced a local edema that increased progressively $(31.55 \pm 4.07 \%$, $49.44 \pm 6.38 \%, 61.97 \pm 5.37 \%$ and $71.68 \pm 3.55$ $\%$ after $1,2,3$ and $4 \mathrm{~h}$, respectively) to reach a maximal after $5 \mathrm{~h}(82.20 \pm 3.04 \%)$, (Figure 2). The oral administration of diclofenac $(10 \mathrm{mg} / \mathrm{kg})$ significantly inhibited inflammatory response in rats when compared to the control rats $(p<$ $0.001)$ at $3 \mathrm{~h}$ of treatment until $6 \mathrm{~h}(p<0.01)$. Rats treated with $T$. communis $(150,300$ and $600 \mathrm{mg} / \mathrm{kg}$ ) failed to produce any significant 
decrease in paw edema when compared to control rats.

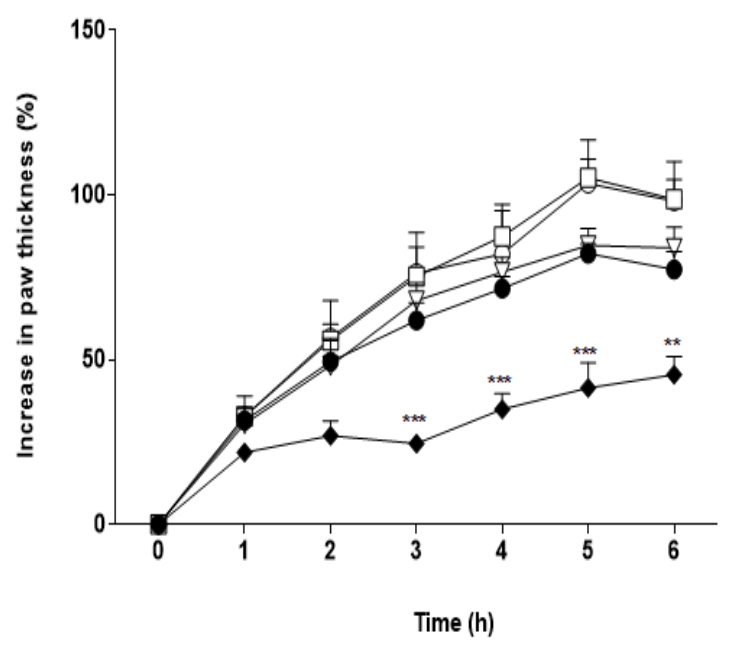

Figure 2: Effect of various doses of $T$. communis (TC) on carrageenan-induced paw edema. - $\bullet-$, control; - -, diclofenac; - $\nabla$-, TC (150 mg/kg); - $\square$-, TC $(300 \mathrm{mg} / \mathrm{kg}) ;-O-$, TC $(600 \mathrm{mg} / \mathrm{kg})$. Edema was monitored at $1 \mathrm{~h}$ intervals over $6 \mathrm{~h}$ as increase percentage in paw thickness. Data are presented as mean \pm SEM $(n=5) .{ }^{* * *} p<0.001$ and ${ }^{* *} p<0.01$ when compared with control rats.

\section{Formaldehyde-induced arthritis}

The effect of $T$. communis methanol extract on formaldehyde-induced paw edema is shown in figure 3. Subplanter injection of formaldehyde $(0.1 \mathrm{~mL})$ on day 1 and 3 to the rat hind paw led to increase in paw thickness. In the control group, the maximum increase in paw thickness are $74.29 \pm 7.00 \%$ and then starts decreasing. Aspirin significantly suppressed the joint swelling when compared with arthritic control between day $4(p<0.001)$ and day $10(p<0.05)$, after formaldehyde treatment when compared to the control. The group treated with $T$. communis $(150 \mathrm{mg} / \mathrm{kg})$ showed significant reduction in paw thickness only on day $2(p<0.01)$ and day $4(p<$ 0.05). However, the group treated with $T$. communis 300 and $600 \mathrm{mg} / \mathrm{kg}$ did not show any significant reduction in paw thickness.

\section{Adjuvant-induced arthritis}

\section{Effect of T. communis extract on body weight}

The mean change in the body weight is shown in Figure 4. In comparison to AIA group, the normal rats exhibited increases in body weight up to day $8(p<0.001)$. The groups treated with $T$. communis extract and diclofenac did not show any significant increase in body weight.

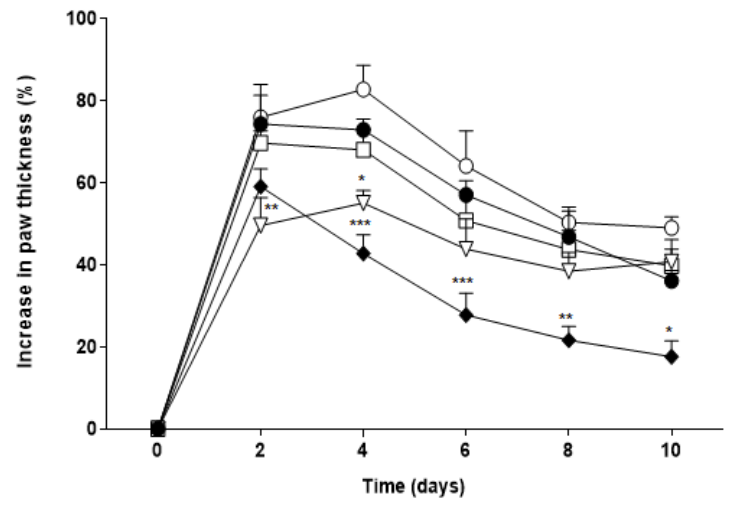

Figure 3: Effect of various doses of $T$. Communis (TC) on formaldehyde-induced paw edema. -•-, control; - $\mathrm{mg} / \mathrm{kg}) ;-\square-$, TC (300 mg/kg); -O-, TC (600 $\mathrm{mg} / \mathrm{kg}$ ). Data are presented as mean \pm SEM. ( $n$ $=5) .{ }^{\star \star \star} p<0.001,{ }^{\star *} p<0.01$ and ${ }^{*} p<0.05$.

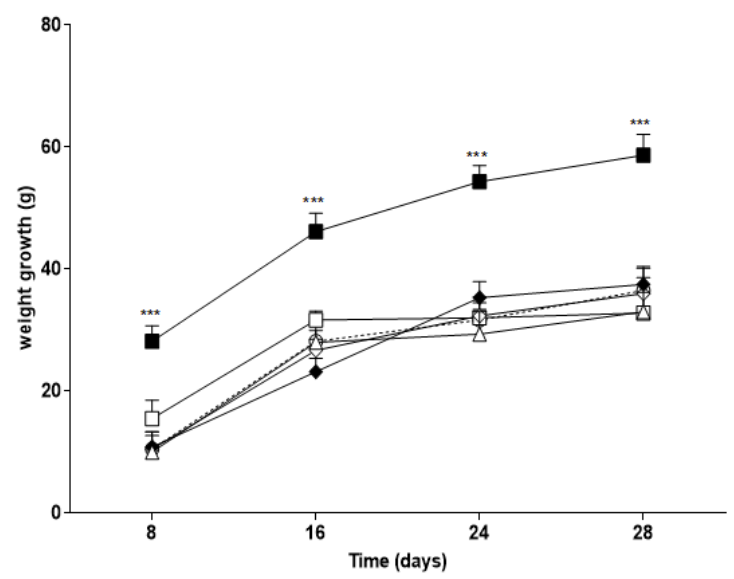

Figure 4: Effect of various doses of T. communis (TC) on body weight changes in adjuvantinduced arthritis. - $\Delta-$, AIA; -n-, normal; - -, diclofenac; - $\diamond-$, TC (150 mg/kg); - $\square-$, TC (300 $\mathrm{mg} / \mathrm{kg}) ;$..o.., TC $(600 \mathrm{mg} / \mathrm{kg})$. The weight increase was calculated as follows: $\Delta(\mathrm{g})=$ weight (day 8, 16, 24, 28) - initial weight (day 0). Data is presented as mean \pm SEM. $(n=6) .{ }^{* * *} p<$ 0.001 when compared to AIA rats

\section{Effect of T. communis extract on hind paw swelling}

The administration of FCA into the subplantar region induced arthritis and increased the paw volume observed from the day 4 until the end of the study (Figure 5). The diclofenac-treated group showed significant $(p<0.01)$ reduction in paw volume from the day 16 after immunization (3.94 $\pm 5.22 \%)$ to the day $28(35.67 \pm 6.34 \%)$ when compared with AIA group (74.36 $\pm 13.17 \%$ and $89.15 \pm 11.25 \%$, respectively). The animals treated with $T$. communis extract $(150 \mathrm{mg} / \mathrm{kg})$ showed significant improvement in joint swelling 
$(p<0.01)$ on $28^{\text {th }}$ day, whereas, the rest of doses did not show any effect.

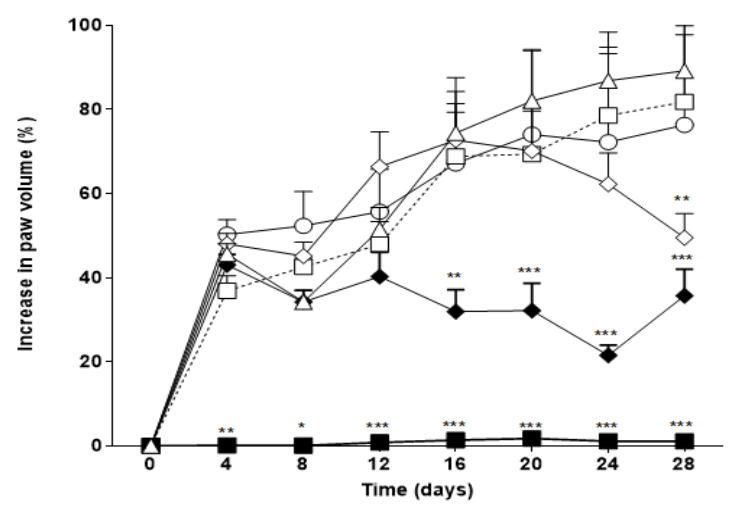

Figure 5: Effect of various doses of $T$. communis (TC) on ankle diameter in adjuvant induced arthritis. - $\Delta$-, AIA; -ш-, normal; - --, diclofenac; - $\diamond$-, TC (150 mg/kg); - $\square-$, TC (300 mg/kg); -o-, TC $(600 \mathrm{mg} / \mathrm{kg})$. Data are presented as mean \pm SEM. $(n=6) .{ }^{\star * *} p<0.001,{ }^{\star *} p<0.01$ and ${ }^{*} p<$ 0.05 when compared with AIA rats

\section{Effect of T. communis on arthritis scores}

To assess the severity of arthritis, arthritis scores were evaluated. The normal rats presented no swelling. The total arthritis score in AIA group was increased on day12 after induction of arthritis. The peak incidence occurred on day 20 after immunization. Treatment with diclofenac (3 $\mathrm{mg} / \mathrm{kg})$ significantly $(p<0.01)$ suppressed swelling on day 12 to the day $28(p<0.001)$ when compared with AIA group. However, groups treated with $T$. communis (150, 300 and $600 \mathrm{mg} / \mathrm{kg}$ ) slowly decreased the swelling when compared to the AIA group (Figure 6).

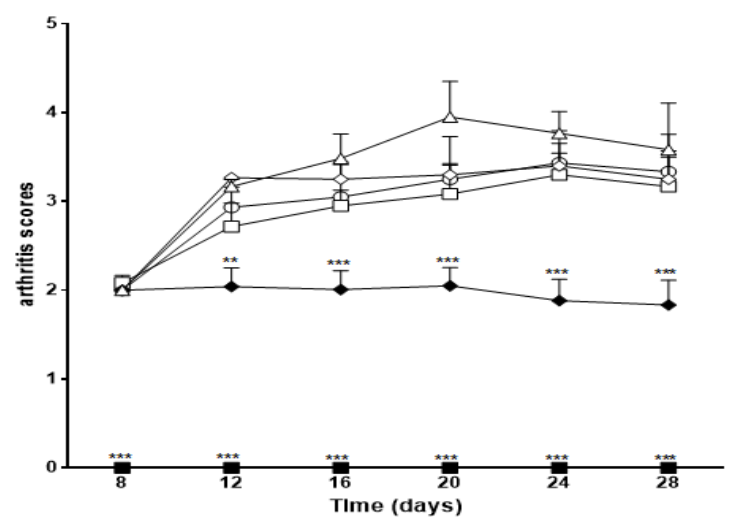

Figure 6: Effect of various doses of $T$. communis on arthritis scores in adjuvant-induced arthritis. $\Delta$-, AIA; -ш-, normal; - --, diclofenac; - $\diamond-$, TC (150 $\mathrm{mg} / \mathrm{kg}) ;-\square-, \quad$ TC $(300 \mathrm{mg} / \mathrm{kg}) ;-$-o-, TC (600 $\mathrm{mg} / \mathrm{kg})$. Data are presented as mean \pm SEM. ( $n$ $=6) .{ }^{* * *} p<0.001$ and ${ }^{* *} p<0.01$ when compared with AIA rats
Evaluation of $T$. communis effect on spleen index

The spleen index is associated with immunological functions. It was determined on day 28 after FCA injection. The results showed that the spleen index of the AIA group was increased compared with normal group (Figure 7). Rats treated with diclofenac (3 $\mathrm{mg} / \mathrm{kg}$ ) showed mild decrease in the spleen index. Moreover, administration of $T$. communis extract (150, 300 and $600 \mathrm{mg} / \mathrm{kg}$ ) showed no significant effect on the spleen index when compared with AIA group.

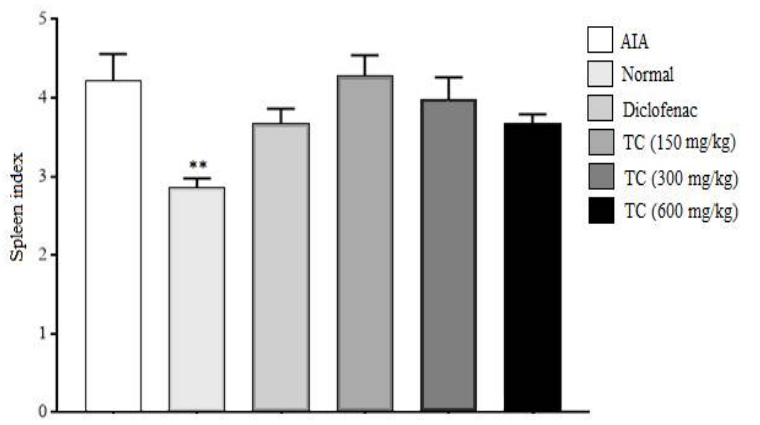

Figure 7: Effect of various doses of T. communis (TC) on the spleen indices in adjuvant induced arthritis (mg/kg body weight). Data are presented as mean \pm SEM $(n=6) .{ }^{* *} p<0.01$ compared with AIA rats

\section{DISCUSSION}

Phenols and polyphenolic compounds, such as flavonoids, are widely present in plant-derived food products and they have been shown to possess significant antioxidant activities [16]. In the present study, the total phenolic and flavonoid contents of $T$. communis were $55.2 \pm$ $0.036 \mathrm{mg} \mathrm{GAE} / \mathrm{g}$ and $1.191 \pm 0.002 \mathrm{mg} \mathrm{QE} / \mathrm{g}$, respectively. In previous reports, total phenolic and flavonoid contents in $T$. communis methanol extract were found $26.55 \pm 3.93 \mathrm{mg} \mathrm{AGE} / \mathrm{g}$ and $10.2 \pm 0.1 \mathrm{mg} \mathrm{QE} / \mathrm{g}$, respectively [17]. Differences in the amounts of these compounds could be due to the season of the collection of the plants.

The DPPH scavenging assay is based on donating protons of antioxidants to neutralize $\mathrm{DPPH}$ radical. The reaction is accompanied by colour change of the DPPH measured at $517 \mathrm{~nm}$, and the discolouration serves as an indicator of the antioxidant efficacy [18]. In the present study, BHT $(0.087 \pm 0.001 \mathrm{mg} / \mathrm{mL})$ showed better scavenging activity than the $T$. communis extract $(0.128 \pm 0.011 \mathrm{mg} / \mathrm{mL})$. It was evident that the extract showed good free radical scavenging activity to act as antioxidant. The antioxidant 
activity might be due to the presence of poly phenols in the $T$. communis extract.

In the $\beta$-Carotene bleaching assay, $T$. communis exhibited marked antioxidant activity, comparable to that of BHT. This result indicates that the extract had acted as an effective antioxidant in a $\beta$-carotene linoleic acid model system. It has been reported that phenolic compounds are the main class of natural antioxidants and there is a close positive correlation between the phenolic content and antioxidant activity of plant extracts [19].

Carrageenan-induced rat paw edema assay is accepted as useful phlogistic tool for the study of new anti-inflammatory drugs [20]. In this study diclofenac showed the inhibition of rat paw edema from $3 \mathrm{~h}$ until $6 \mathrm{~h}$ of experiment. However, rats treated with $T$. communis extract $(150,300$ and $600 \mathrm{mg} / \mathrm{kg})$ did not show inhibition of rat paw edema. In a previous study, neither aqueous nor ethanol extracts prepared from roots of $T$. communis showed any remarkable anti-inflammatory activity in carrageenan-induced paw edema in mice [21]. Therefore, these results confirm that $T$. communis had not antiinflammatory activity in carrageenan-induced paw edema assay.

Formaldehyde-induced paw edema is the model used for chronic inflammation. It is very similar to arthritis and is used to screen anti-arthritic and anti-inflammatory agents [22]. In the current study, aspirin exhibited inhibitions of the rat hind paw edema. T. communis extract at dose of 150 $\mathrm{mg} / \mathrm{kg}$ showed inhibition of rat paw edema only on $2^{\text {th }}$ and $4^{\text {th }}$ day. However, the extract at doses of 300 and $600 \mathrm{mg} / \mathrm{kg}$ did not show any remarkable anti-inflammatory activity.

Adjuvant-induced arthritis by complete Freund's adjuvant is known to simulate the immunological and biochemical features of rheumatoid arthritis [23]. Limb swelling, inflammatory cell infiltration, proliferative synovitis and the bone and cartilage erosion are clinical signs common of human arthritis and adjuvant-induced arthritis rat. Owing to this similarity in pathologic features, adjuvantinduced arthritis rat is a model of rheumatoid arthritis widely used in evaluating the efficacy of anti-inflammatory drugs [24]. In adjuvant induced arthritis, paw swelling and arthritic scores are parameters of measuring the anti-arthritic activity of various tested drugs and used here to evaluate the activity of $T$. communis extract. Treatment with $\mathrm{T}$. communis extract revealed that only the dose $150 \mathrm{mg} / \mathrm{kg}$ exhibits a significant decrease in the paw thickness on day 28. In addition, the groups treated with $T$. communis extract did not show significant increases in body weight when compared with the AIA model group. The increase in spleen weight of AIA rats has been reported to be associated with splenomegaly, generalized lymphadenopathy and altered hepatic function [25]. In this study, administration of $T$. communis extract $(150,300$ and $600 \mathrm{mg} / \mathrm{kg}$ ) showed no significant decrease in the spleen index.

\section{CONCLUSION}

Total phenolic and flavonoid contents, free radical scavenging activity and inhibition of $\beta$ carotene bleaching show that the methanol extract of $T$. communis exhibits antioxidant activity. The antioxidant activities of the extract can be ascribed to the phenolic compounds. However, the results of in vivo studies reveal that the extract of $T$. communis does not show antiinflammatory and anti-arthritic effects in animal models. Hence, these results did not support its use in the traditional system of medicine against rheumatoid arthritis in Algeria.

\section{DECLARATIONS}

\section{Acknowledgement}

The authors acknowledge the Algerian Ministry of Higher Education and Scientific Research (MESRS, DGRSDT) for their financial support during the period of the research.

\section{Conflict of interest}

No conflict of interest is associated with this work.

\section{Contribution of authors}

We declare that this work was done by the authors named in this article and all liabilities pertaining to claims relating to the content of this article will be borne by the authors. We also declare that all authors read and approved the manuscript for publication.

\section{Open Access}

This is an Open Access article that uses a funding model which does not charge readers or their institutions for access and distributed under the terms of the Creative Commons Attribution License (http://creativecommons.org/licenses/by/ 4.0) and the Budapest Open Access Initiative (http://www.budapestopenaccessinitiative.org/rea d), which permit unrestricted use, distribution, 
and reproduction in any medium, provided the original work is properly credited.

\section{REFERENCES}

1. Alam MN, Bristi NJ, Rafiquzzaman M. Review on in vivo and in vitro methods evaluation of antioxidant activity. Saudi Pharm J 2013; 21: 143-152.

2. Lee J, Koo N, Min DB. Reactive oxygen species, aging, and antioxidative nutraceuticals. Compr Rev Food Sci Food Saf 2004; 3:21-33.

3. Gülçin I. Antioxidant activity of food constituents: an overview. Arch Toxicol 2012; 86: 345-391.

4. Tristano AG. Tyrosine kinases as targets in rheumatoid arthritis. Int Immunopharmacol 2009; 9:1-9.

5. Khanna D, Sethi G, Ahn KS, Pandey MK, Kunnumakkara $A B$, Sung $B$, Aggarwal A, Aggarwal BB. Natural products as a gold mine for arthritis treatment. Curr Opin Pharmacol 2007; 7(3): 344-51.

6. Duke JA. CRC Handbook of Medicinal Herbs, 2nd edn. CRC Press: Boca Raton FL. 2002.

7. Aouachria S, Boumerfeg S, Benslama A, Benbacha F, Guemmez T, Khennouf S, Arrar L, Baghiani A. Acute, sub-acute toxicity and antioxidant activities (in vitro and in vivo) of Reichardia picroide crude extract. J Ethnopharmacol 2017; 208: 105-116.

8. OECD [Organisation for Economic Co-operation and Development]. Guideline for testing of chemicals. Acute Oral Toxicity - Acute Toxic Class Method, No. 423, Paris 2001.

9. Boussoualim N, Baghiani A, Krache I, Trabsa $H$, Khennouf S, Arrar L. Inhibitory effects of Anchusa azurea extracts on xanthine oxidase activity and its hypouricemic effects on mice. Int $\mathrm{J}$ Pharm Pharm Sci 2015; 7(8):195-199.

10. Buodonpri W, Wichitnithad W, Rojsitthisak $P$, Towiwat $P$. Synthetic curcumin inhibits carrageenan-induced paw edema in rats. $J$ Health Res 2009; 23:11-6.

11. Akindele AJ and Adeyemi OO. Anti-inflammatory activity of the aqueous leaf extract of Byrsocarpus coccineus. Fitoterapia 2007; 78: 25-28.

12. Pan K, Xia X, Guo W, Kong L. Suppressive effects of total alkaloids of Lycopodiastrum casuarinoides on adjuvant-induced arthritis in rats. J Ethnopharmacol 2015; 159: 17-22.

13. Bendele AM. Animal models of rheumatoid arthritis. $J$ Musculoskel Neuron Interact 2001; 1(4): 377-385.
14. Tang $L Q$, Wei $W$, Wang $X Y$. Effects and mechanisms of catechin for adjuvant arthritis in rats. Adv Ther 2007; 24: 679-690.

15. Zhang LL, Wei W, Yan SX, Hu XY, Sun WY. Therapeutic effects of glucosides of Cheanomeles speciosa on collagen-induced arthritis in mice. Acta Pharmacol Sin 2004; 25(11):1495-501.

16. Van Acker SABE, Van Den Berg D, Tromp MNJL, Griffioen DH, Van Bennekom WP, Van Der Vijgh WJF, Bast A. Structural aspects of antioxidant activity of flavonoids. Free Radical Bio 1996; 20(3): 331-342.

17. Boumerfeg S, Baghiani A, Messaoudi D, Khennouf S, Arrar L. Antioxidant properties and xanthine oxidase inhibitory effects of Tamus communis $L$. root extracts. Phytother Res 2009; 23: 283-288.

18. Shahidi F, Zhong Y. Measurement of antioxidant activity. J Funct Foods 2015; 18: 757-781.

19. Zhao HX, Zhang HS, Yang SF. Phenolic compounds and its antioxidant activities in ethanolic extracts from seven cultivars of Chinese jujube. Food Sci Human Wellness 2014; 3: 183-190.

20. Sindhu G, Ratheesh M, Shyni GL, Nambisan B, Helen A. Anti-inflammatory and antioxidative effects of mucilage of Trigonella foenum graecum (Fenugreek) on adjuvant induced arthritic rats. Int Immunopharmacol 2012; 12(1): 205-211.

21. Kupeli E, Orhan I, Yesilada E. Evaluation of some plants used in Turkish folk medicine for their anti-inflammatory and antinociceptive activities. Pharm Biol 2007; 45: 547555.

22. Greenwald RA. Animal models for evaluation of arthritic drugs. Methods find. Exp Clin Pharmacol 1991; 13: 75 83.

23. Ramprasath VR, Shanthi $P$, Sachdanandam $P$. Immunomodulatory and anti-inflammatory effects of Semecarpus anacardium LINN. Nut milk extract in experimental inflammatory conditions. Biol Pharm Bull 2006; 29(4): 693-700.

24. Pearson CM, Wood FD. Studies of polyarthritis and other lesions induced in rats by injection of mycobacterial adjuvant: I. General clinical and pathologic characteristics and some modifying factors. Arthritis Rheum 1959; 2: 440-459.

25. Whitehouse MW, Orr KJ, Beck FW, Pearson CM. Freund's adjuvants: relationship of arthritogenicity and adjuvanticity in rats to vehicle composition. Immunol 1974; 27(2): 311-330. 